\title{
Os fatores que contribuem para os casos de reincidência das violências doméstica no Centro de Atendimento à Mulher - CAM do município de Vilhena/RO
}

\author{
Recebido em 24/10/2019, aprovado em 17/12/2019 \\ DOI: $10.30612 / m v t . v 7 i 12.10567$ \\ Edimilson Lopes de Meira'
}

RESUMO: A violência doméstica é uma questão histórica, social e cultural, que ainda hoje faz parte da realidade de muitas mulheres em lares brasileiros. Nesse sentido, o objetivo do presente estudo é conhecer o contexto histórico e atual das violências doméstica através de pesquisa bibliográfica, bem como verificar os fatores que contribuem para os casos de reincidência das violências doméstica, especificamente, no Centro de Atendimento à Mulher - CAM do município de Vilhena/ RO. Assim sendo, para se chegar ao objetivo proposto este estudo perpassa por temáticas como: conceituação da violência, formas de violências, políticas públicas de enfrentamento a violência doméstica incluindo a lei Maria da penha. Destarte, também é objetivo do trabalho tratar as violências doméstica e familiar sob diferentes ângulos, pois, embora, tenham ocorrido avanços no trato desta questáo é preciso divulgar e levar ao conhecimento da sociedade os direitos de proteção garantidos pela lei às mulheres vitimadas.

Palavras-chave: Violências Doméstica. Mulher. Reincidência. Enfrentamento das Violências.

\section{Factors contributing to case reincidence cases in the Vilhena / RO city women's care center}

ABSTRACT: Domestic violence is a historical, social and cultural issue that is still part of the reality of many women in Brazilian homes. In this sense, the objective of the present study is to know the historical and current context of domestic violence through bibliographic research, as well as to verify the factors that contribute to the cases of recurrence of domestic violence, specifically, at the Women's Care Center - CAM do municipality of Vilhena / RO. Thus, in order to reach the proposed objective, this study goes through themes such as: conceptualization of violence, forms of

1 Graduado em Serviço Social pela Faculdade da Amazônia (2012). Pós-Graduado em Gestão Estratégica na Área Social pela Faculdade Educacional da Lapa - FAEL, (2014). Pós-Graduado em Educaçáo Empreendedora pela Pontifícia Universidade Católica do Rio de Janeiro-PUC/RJ, (2017). Mestrando em Assessoria de Administração pelo Instituto Politécnico do Porto-IPP Portugal. Atualmente, sou Assistente Social do Instituto Federal de Educação, Ciência e Tecnologia de Rondônia-IFRO, Campus Vilhena, desde 2013. E-mail:edimilson.meira@ifro.edu.br 
violence, public policies to confront domestic violence including the Maria da penha law. Thus, it is also the objective of this work to treat domestic and family violence from different angles, because, although there have been advances in addressing this issue, it is necessary to disclose and bring to society the rights of protection guaranteed by the law to victims.

Keywords: Domestic Violence. Woman. Recurrence. Facing Violence.

\section{Factores que contribuyen a casos de casos de reincidencia en el centro de cuidado de mujeres de Vilhena / RO city}

RESUMEN: La violencia doméstica es un problema histórico, social y cultural que todavía es parte de la realidad de muchas mujeres en los hogares brasileńos. En este sentido, el objetivo del presente estudio es conocer el contexto histórico y actual de la violencia doméstica a través de la investigación bibliográfica, así como verificar los factores que contribuyen a los casos de recurrencia de la violencia doméstica, específicamente, en el Women's Care Center - CAM do municipio de Vilhena / RO. Por lo tanto, para alcanzar el objetivo propuesto, este estudio aborda temas como: conceptualización de la violencia, formas de violencia, políticas públicas para enfrentar la violencia doméstica, incluida la ley Maria da penha. Por lo tanto, también es el objetivo de este trabajo tratar la violencia doméstica y familiar desde diferentes ángulos, porque, aunque ha habido avances para abordar este problema, es necesario revelar y llevar a la sociedad los derechos de protección garantizados por la ley a las víctimas.

Palabras clave: violencia doméstica. Mujer Recurrencia Enfrentando la violencia.

\section{INTRODUÇÃO}

A motivação para a elaboração deste artigo foi o fato de ser uma questão de alta complexidade e relevância social e profissional, visto que, há uma persistência de situaçôes de violências contra a mulher ao longo do tempo. Dessa forma, acredito que estudos, como é o caso deste artigo, podem contribuir para qualificar a intervenção do assistente social e melhorar a formulação de políticas públicas dirigidas a esse segmento significativo da população brasileira.

Na primeira parte do trabalho, preocupou-se em pesquisar os conceito e as formas das violências, a fim de obtermos um maior embasamento para tratar das violências contra a mulher, visto que nenhum fenômeno formado no interior da sociedade pode ser apreendido fora de um contexto histórico e social. Após a conceituação apresentamos uma breve exposição quanto ao contexto atual das políticas públicas voltadas ao enfrentamento das violências contra a mulher e as inovaçóes da "Lei Maria da Penha” que, dentre outras questôes, define os tipos de violência perpetrada contra a mulher e as puniçóes prescritas ao agressor.

Para finalizar este trabalho de pesquisa, buscou-se conhecer e analisar os fatores que contribuem para a reincidência das violências doméstica no Centro de Atendimento à Mulher - CAM 
no município de Vilhena/RO. Para alcançarmos o objetivo, foi feito um levantamento de dados constantes nas fichas das mulheres atendidas em 2018.

\section{REVISÃO DE LITERATURA}

\section{VIOLÊNCIAS DOMÉSTICA}

O presente tópico nos servirá como base conceitual para o desenvolvimento da pesquisa, embasando em autores e legislação que trata sobre o tema violências domésticas.

Nessa perspectiva Teles e Melo (2003), destacam que violência é o uso da força física, psicológica ou intelectual para obrigar a outra pessoa a fazer algo contra a sua vontade; é impedir a outra pessoa de manifestar seu desejo e sua vontade. É um meio de manter a outra pessoa sob seu domínio. No que se refere à violência doméstica pode-se recorrer ao dispositivo legal que trata do tema em questão para que se possa definir de forma especifica. Assim, vejamos o que diz a Lei 11.340/2006:

Art. 5ำ Para os efeitos desta Lei, configura violência doméstica e familiar contra a mulher qualquer ação ou omissão baseada no gênero que lhe cause morte, lesão, sofrimento físico, sexual ou psicológico e dano moral ou patrimonial: I - no âmbito da unidade doméstica, compreendida como o espaço de convívio permanente de pessoas, com ou sem vínculo familiar, inclusive as esporadicamente agregadas; II no âmbito da família, compreendida como a comunidade formada por indivíduos que são ou se consideram aparentados, unidos por laços naturais, por afinidade ou por vontade expressa; III - em qualquer relação íntima de afeto, na qual o agressor conviva ou tenha convivido com a ofendida, independentemente de coabitação. Parágrafo único. As relaçóes pessoais enunciadas neste artigo independem de orientação sexual. (BRASIL, 2006)

A partir desta perspectiva conceitual da Legislação, nota-se que é necessário que a ação ou omissão aconteça no seio familiar ou doméstico ou por motivo de qualquer relação intima de afeto na qual o agressor conviva ou tenha convivido com a ofendida, independente de coabitação.

Assim sendo, em consonância com o preceito legal, as violências domésticas são representadas pelas formas de abusos físico, sexual, psicológico, emocional e econômico no meio da família, onde se faz refletir principalmente na autoestima das mulheres e destrói sua saúde, ocasionando-lhes danos às vezes, irreparáveis. Náo obstante, impede o desenvolvimento social das mulheres, diminuindo a sua participação na sociedade e tornando-as mais temerosas fazendo com que se tornem inseguras diante das adversidades da vida.

Nesse sentido, Queiroz (2008) pondera que violência pode assumir diferentes papéis e variadas características e tem como definição o exercício da força em contrariedade às leis vigentes, para constranger ou submeter uma pessoa àquilo que ela não queira. Nada obstante, Machado e Gonçalves, complementa este entendimento sobre violência doméstica e traz a seguinte fala:

Considera-se violência doméstica qualquer ato, conduta ou omissão que sirva para infligir sofrimentos físicos, sexuais, mentais ou econômicos, de modo direto ou indireto a qualquer pessoa que habite no mesmo agregado doméstico privado ou que, não habitando no mesmo agregado doméstico privado que o agente da 
violência seja cônjuge ou companheiro marital ou ex-cônjuge ou ex-companheiro marital (MACHADO e GONÇALVES, 2003, p.45).

Ainda discorrendo a respeito da conceituação da temática em questão, de modo geral entende-se que a violência caracteriza-se como uma questão social grave e delicada, presente no cotidiano de mulheres em vários países. Além do mais, esteve presente em todos os períodos de nossa história. Pode ser física, psicológica, sexual, urbana, institucional, intrafamiliar, de trânsito, enfim, pode desencadear-se de diversas maneiras.

\section{FORMAS DE VIOLÊNCIA DOMÉSTICA CONTRA A MULHER}

Quanto às formas de violência doméstica contra a mulher, as mais comuns são a física, psicológica e/ou emocional, sexual, patrimonial e moral, (Lei 11.340/2006), essas são as formas de violências disciplinadas pela legislação e por serem as mais comuns foram incluídas na letra da lei.

A violência física é a forma mais banal e identificável no cotidiano, pois, concerne no ato de provocar lesôes corporais possivelmente diagnosticáveis, tais como cutâneas, neurológicas, oculares e ósseas, provocadas por queimaduras, mordidas, tapas, espancamentos, ou qualquer ação que ponha em risco a integridade física da mulher. (CUNHA, 2007, p. 37)

Segundo o art. $7^{\circ}$ da lei 11.340 inciso I "a violência física, entendida como qualquer conduta que ofenda sua integridade ou saúde corporal”. Não obstante, segundo o mesmo dispositivo legal ora citado em seu inciso II define que:

A violência psicológica, entendida como qualquer conduta que lhe cause danos emocional e diminuição da autoestima ou que lhe prejudique e perturbe o pleno desenvolvimento ou que vise degradar ou controlar suas açóes, comportamentos, crenças e decisões, mediante ameaça, constrangimento, humilhação, manipulação, isolamento, vigilância constante, perseguição contumaz, insulto, chantagem, ridicularizaçáo, exploração e limitação do direito de ir e vir ou qualquer outro meio que lhe cause prejuízo à saúde psicológica e à autodeterminação.

Assim sendo, é possível perceber que de acordo com esse conceito da lei Maria da Penha a violência psicológica se expressa através da tentativa de controlar as ações, crenças e decisóes, por meio de intimidação, manipulação, ameaças dirigidas a vítima ou a seus filhos, humilhação, isolamento, rejeição, exploração e agressão verbal, entre outras.

Outro tipo de violência conceituada pela Lei 11.340/2006 é a patrimonial: "A violência patrimonial, entendida como qualquer conduta que configure retenção, subtração, destruição parcial ou total de seus objetos, instrumentos de trabalho, documentos pessoais, bens, valores e direitos ou recursos econômicos, incluindo os destinados a satisfazer suas necessidades".

Segundo o que preceitua a referida Lei a violência patrimonial pode resultar em danos, perdas, subtração ou retenção de objetos, documentos pessoais, bens e valores da mulher. É uma forma de violência que pode ser visualizada através de situaçóes como quebrar móveis ou eletrodomésticos, rasgar roupas e documentos, ferir ou matar animais de estimação, tomar imóveis e dinheiro, ou, até, não pagar pensão alimentícia.

Ainda discorrendo sobre as forma de violência à luz da Lei 11.340/2006 cabe destacar umas das formas mais repugnantes, qual seja a violência sexual conceituada como: 
A violência sexual, entendida como qualquer conduta que a constranja a presenciar, a manter ou a participar de relação sexual não desejada, mediante intimidação, ameaça, coação ou uso da força; que a induza a comercializar ou a utilizar, de qualquer modo, a sua sexualidade, que a impeça de usar qualquer método contraceptivo ou que a force ao matrimônio, à gravidez, ao aborto ou à prostituição, mediante coação, chantagem, suborno ou manipulação; ou que limite ou anule o exercício de seus direitos sexuais e reprodutivos; (BRASIL, 2006).

Desta feita, a violência sexual se manifesta como: "expressóes verbais ou corporais que não são do agrado da pessoa; toques e carícias não desejados; exibicionismo e voyeurismo; prostituição forçada; participação forçada em pornografia; relaçóes sexuais forçadas - coerção física ou por medo do que venha a ocorrer" (TAQUETTE, 2007, p. 49).

No que se refere à violência moral, também, prescrita na legislação supracitada. Denota-se como qualquer conduta que configure calúnia, difamação ou injúria.

\title{
POLÍTICAS PÚBLICAS DE ENFRENTAMENTO DA VIOLÊNCIA DOMÉSTICA
}

Segundo o que dispóe a Política Nacional de Enfrentamento à Violência, a Lei Maria da Penha prevê políticas públicas de enfrentamento à violência doméstica e familiar contra a mulher organizada em rede de atendimento, desta feita

\begin{abstract}
A assistência à mulher em situação de violência doméstica e familiar será prestada de forma articulada e conforme os princípios e as diretrizes previstos na Lei Orgânica da Assistência Social, no Sistema Único de Saúde, no Sistema Único de Segurança Pública, entre outras normas e políticas públicas de proteção, e emergencialmente quando for o caso (BRASIL, 2006).
\end{abstract}

Além disso, a Lei estabelece a criação de serviços especializados no atendimento dos casos de violência doméstica e familiar contra a mulher, tais como: centros de referência de atendimento à mulher; casas-abrigo/serviços de abrigamento; núcleos de defensoria pública; serviços de saúde e centros de perícia médico-legal especializado; centros de educação e reabilitação dos agressores centros de responsabilizaçáo e educação dos agressores (todos previstos no art. 35) e juizados de violência doméstica e familiar contra a mulher (art. 29).

E por se tratar de uma norma jurídica, vislumbra-se que a previsão de criação de serviços especializados reforça a responsabilidade de os governos (em especial, estaduais e municipais) implantarem políticas públicas de enfrentamento à violência contra as mulheres e formaliza a necessidade de uma rede articulada e intersetorial de atendimento à mulher em situação de violência.

Nessa perspectiva, a criaçáo do Centro de Atendimento à Mulher representou a instauração de um novo elo da Rede de Atendimento às Mulheres em Situação de Violência, ao lado de serviços como casas abrigo, centros de referência de atendimento à mulher e delegacias de polícia. Além de proporcionar uma maior visibilidade dos serviços da rede de atendimento para a populaçáo em geral e para as mulheres em situação de violência e de funcionar como uma porta-de-entrada.

Assim, é possível afirmar que as políticas públicas de enfrentamento a violência doméstica constitui uma ampla rede de atendimento às mulheres em situação de violência doméstica contemplando o eixo da "assistência" que, segundo o previsto na Política Nacional de Enfrentamento à Violência contra as Mulheres, objetiva: 
(...) garantir o atendimento humanizado e qualificado às mulheres em situação de violência por meio da formação continuada de agentes públicos e comunitários; da criação de serviços especializados (Casas-Abri go/Serviços de Abrigamento, Centros de Referência de Atendimento à Mulher, Serviços de Responsabilização e Educação do Agressor, Juíza dos de Violência Doméstica e Familiar contra a Mulher, Defensorias da Mulher, Delegacias Especializadas de Atendimento à Mulher); e da constituição/fortalecimento da Rede de Atendimento (articulação dos governos - Federal, Estadual, Municipal, Distrital- e da sociedade civil para o estabelecimento de uma rede de parcerias para o enfrentamento da violência contra as mulheres, no sentido de garantir a integralidade do atendimento (SPM, 2007, p. 8).

Nesse sentido, cabe destacar os quatro principais setores/áreas que estão divididos a rede de atendimento à mulher em situação de violências. Conforme preconiza a Política Nacional de Enfrentamento à Violência contra as Mulheres são: saúde, justiça, segurança pública e assistência social.

Dentro deste contexto da referida Política, destaca-se os serviços náo especializados de atendimento à mulher, que, em geral, constituem a porta de entrada da mulher na rede (a saber, hospitais gerais, serviços de atenção básica, programa saúde da família, delegacias comuns, polícia militar, polícia federal, Centros de Referência de Assistência Social/CRAS, Centros de Referência Especializados de Assistência Social/CREAS, Ministério Público, defensorias públicas).

Não obstante, citam-se ainda os serviços especializados de atendimento à mulher que são aqueles que atendem exclusivamente a mulheres e que possuem especialização no tema da violência contra as mulheres.

Assim, a rede de atendimento especializado é composta por Centros de Atendimento à Mulher em situação de violência (Centros de Referência de Atendimento à Mulher, Núcleos de Atendimento à Mulher em situação de Violência, Centros Integrados da Mulher), Casas Abrigo, Casas de Acolhimento Provisório (Casas-de-Passagem), Delegacias Especializadas de Atendimento à Mulher (Postos ou Seçóes da Polícia de Atendimento à Mulher), Núcleos da Mulher nas Defensorias Públicas, Promotorias Especializadas, Juizados Especiais de Violência Doméstica e Familiar contra a Mulher, Central de Atendi mento à Mulher - Ligue 180, Ouvidoria da Mulher, Serviços de saúde voltados para o atendimento aos casos de violência sexual e doméstica, Posto de Atendimento Humanizado nos aeroportos (tráfico de pessoas) e Núcleo de Atendimento à Mulher nos serviços de apoio ao migrante. (SPM, 2010, p. 15-16).

Assim sendo, vislumbra-se que as políticas públicas de enfrentamento à violência contra as mulheres é marcada pela multiplicidade de serviços e de instituiçóes. Nesse sentido, forma um paradoxo social entre os mecanismos de enfrentamento da problemática ora citada e o agravamento da violência constantemente.

Nessa perspectiva, se faz necessário compreender que para a efetivaçáo dos mecanismos de enfrentamento da violência é importante que serviços e instituiçóes atuem de forma articulada e integrada. No âmbito da assistência, é fundamental que os serviços trabalhem a partir de uma perspectiva intersetorial e que definam fluxos de atendimento compatíveis com as realidades locais os quais devem contemplar as demandas das mulheres em suas diversidades. 
A perspectiva da intersetorialidade representa, portanto, um desafio na medida em que insta a uma ruptura com o modelo 'tradicional'2 ${ }^{2}$ de gestão pública, que tende à departamentalização, à desarticulação e à setorialização das açôes e das políticas públicas.

A importância dos serviços articulados em rede no atendimento a mulheres que vivem em situação de violência é, hoje, reconhecida por diversos setores da sociedade e sua manutenção defendida pelas organizaçóes do movimento de mulheres. Considerando a complexidade da questáo, que deve ser analisada do ponto de vista das desigualdades de poder nas relaçóes entre os gêneros, coloca-se ainda como um desafio para as políticas públicas, nessa área, o desenvolvimento de ações de prevenção e combate dessa forma de violência. A experiência de atendimento acumulada pelos serviços acima citados constitui-se numa importante fonte de informaçóes para estudos e análise do problema.

Por meio do resultado e apresentação da pesquisa pretende-se melhor conhecer a realidade das mulheres atendidas no CAM. Com isso espera-se contribuir para a definição de novas estratégias de atuação nessa área, melhorando a estrutura de serviços e programar açôes de combate e prevenção da violência contra a mulher e desvendar os fatores de reincidência de violência doméstica, visto que, as políticas públicas existem.

\section{METODOLOGIA}

Este estudo, de caráter quanti-qualitativo e descritivo, foi desenvolvido no Centro de Atendimento à Mulher (CAM), que é um programa da Secretaria Municipal da Mulher da Prefeitura do Município de Vilhena/RO.

Para este estudo foram utilizadas as fichas individuais das usuárias do CAM, nas quais constam dados pessoais da mulher agredida, informaçôes sobre tipo de violência sofrida, tipo de vínculo do agressor com a mulher, entre outras. Foram analisadas as fichas das mulheres atendidas no segundo semestre de 2018 em número de 50 casos.

A presente pesquisa que teve como objeto de estudo os casos de violência contra a mulher registrados no Centro de Atendimento à Mulher (CAM), da Prefeitura de Vilhena-RO. O objetivo da pesquisa foi traçar o perfil das mulheres atendidas no CAM no que se refere às reincidentes. Nesse sentido as principais características levantadas foram: vínculo afetivo com o agressor, faixa etária das vítimas, renda da vítima, escolaridade da vítima, escolaridade do agressor, período de convivência, tipos de violência sofrida, convivência com o agressor na ocorrência da denúncia.

2 Antes do lançamento da Política Nacional de Enfrentamento à Violência contra as Mulheres em 2007, a atuação dos serviços especializados e não especializados da rede de atendimento tendia a ocorrer de forma desarticulada e setorializada. Com a criação das Câmaras Técnicas de Monitoramento e Gestáo do Pacto Nacional (vide item 'E' desse texto) - que contam com a participação de diferentes instituiçôes e representantes da sociedade civil (tais como: Executivo, Ministério Público, Judiciário, movimento de mulheres, etc.) - as açóes de enfrentamento passam a se dar de forma mais integrada e articulada, a partir de um diagnóstico estadual da violência contra as mulheres e da rede de atendimento, bem como de negociaçóes conjuntas por parte dos diferentes órgãos do governo federal. 


\section{RESULTADO E APRESENTAÇÃO DA PESQUISA}

Nos últimos anos vem crescendo o número de casos de violências doméstica e familiar, muitos destes reincidentes, pois a maioria das mulheres continua a manter um convívio familiar com os seus agressores, seja por intenção de dar continuidade ao relacionamento afetivo, pelo fato de uma das partes envolvidas não conformar-se com o fim do relacionamento, seja por necessidades financeiras.

A fim de prevenir, punir e erradicar a violência contra a mulher, em 2006, foi promulgado a Lei No 11.340, também conhecida como Lei Maria da Penha. Amparadas pela referida lei, as mulheres vítimas de violência podem buscar, além de proteção, a efetivação de seus direitos junto às Delegacias de Atendimento à Mulher, onde geralmente é realizado o registro das ocorrências, investigação das mesmas e, quando necessário, solicitado a aplicação das Medidas Protetivas.

Quanto ao agressor, são tomadas medidas paliativas, dentre elas a persecução penal, podendo ser de ordem privada ou pública, desprovendo-o de um suporte social mediado por açóes interdisciplinares.

Entretanto, com todas essas medidas e amparo legal, muitas mulheres vivem à mercê da continuada violência doméstica. Assim, busca-se através de pesquisa de campo, apresentar os fatores que leva a reincidência e o silencio das mulheres vítima de violência atendidas no Centro de Atendimento à Mulher do município de Vilhena/RO.

\section{CARACTERIZAÇÃO DO CENTRO DE ATENDIMENTO A MULHER - CAM DE VILHENA- RONDÔNIA}

O Centro de Atendimento à Mulher - CAM de Vilhena/RO se caracteriza como uma política pública para as mulheres que sofrem abusos de violência doméstica, pois as mesmas recebem um suporte para enfrentar a situação em que se encontram. São acompanhadas, dedicadamente, por uma equipe multidisciplinar a fim de compreenderem a complexidade dessa problemática social, e, finalmente, fortalecerem-se no objetivo de suprimi-la.

O CAM está organizado em três setores de atendimento: Encaminhamento, Psicologia e Serviço Social. No setor de encaminhamento as mulheres recebem um atendimento inicial durante o qual é feito um breve diagnóstico para levantar suas queixas e demandas, procedendo-se, a partir desse levantamento, ao encaminhamento para os demais setores do CAM ou para outros serviços, quando for o caso, como: Delegacia da Mulher, Conselho Tutelar, Fórum, Unidades Básicas de Saúde e outros, para atendimento complementar ou como encaminhamento definitivo, quando o caso náo se enquadra nos critérios de atendimento do CAM. (SMP, 2010).

$\mathrm{O}$ atendimento no setor de psicologia pode ser tanto individual quanto em grupo, por meio de aconselhamento, orientação e apoio nas situações de conflito. O setor de serviço social presta atendimento individual ou em grupo, e familiar, realizando investigação social para os processos jurídicos e psicológicos, visitas domiciliares, orientação, encaminhamento aos recursos sociais da comunidade e acompanhamento. (SMP, 2010).

Desse modo, o CAM na cidade de Vilhena/RO torna-se um centro de referência e apoio às mulheres vítimas de violência doméstica, pois muitas delas que procuram a instituição estão querendo desabafar, com alguém, a situação em que estão vivendo, sem serem julgadas. Muitas querem apenas uma palavra "amiga", chorar, "colocar para fora" tudo aquilo que estão passando. Além de tudo, também procuram alternativas que as possibilitem sair da situação de violência. 
O Centro de Atendimento à Mulher - CAM está situada na Avenida 34, s/nº, Bairro, Nova Vilhena, e tem como objetivo dar assistência à mulher, vítima de violência doméstica. Criado em março de 2005, o Centro de Referência e Atendimento à Mulher - CAM de Vilhena conta com uma equipe de profissionais das áreas de serviço social, psicologia e assessoria jurídica que oferece atendimento interdisciplinar a mulheres em situação de violência física, sexual, psicológica, moral e patrimonial.

A organização do serviço segue as orientações da Norma Técnica de Uniformização dos Centros de Referência de Atendimento à Mulher em Situação de Violência, editada pelo Governo Federal no ano de 2006 e está em consonância com a Política Nacional de Enfrentamento à Violência Contra a Mulher (SMP, 2010).

\section{RESULTADOS E DISCUSSÃO}

Conforme mostra tabela 1, a faixa etária que predominou entre as mulheres atendidas no CAM, no segundo semestre de 2018, foi a de 36 a 50 anos, seguida da faixa etária de 25 a 35 anos e 18-24 sendo que a média de idade foi de 36 anos.

Tabela 1 - Característica socioeconômica das mulheres atendidas no Centro de Atendimento à Mulher de Vilhena (R0), 2018.

\begin{tabular}{|c|c|c|}
\hline Faixa Etária & Quantidade & Percentual (\%) \\
\hline $18-24$ & 08 & 16 \\
\hline $25-35$ & 12 & 60 \\
\hline $36-50$ & 30 & 30 \\
\hline Renda da Vitima & & 50 \\
\hline Até 01 salário mínimo & 15 & 20 \\
\hline De 01 a 03 salários mínimos & 25 & \\
\hline Acima 03 salários mínimos & 10 & 64 \\
\hline Situação de Trabalho da Vitima & & 12 \\
\hline Empregada* & 32 & 24 \\
\hline Desempregada & 06 & \\
\hline Dona-de-casa & 12 & \\
\hline Escolaridade da Vitima & & 48 \\
\hline Ensino fundamental incompleto & 24 & 26 \\
\hline Ensino fundamental completo & 13 & 24 \\
\hline Ensino médio & 12 & 02 \\
\hline Analfabeto & 01 & \\
\hline
\end{tabular}

Inclui empregadas no mercado formal, trabalhadoras informais e autônomas.

Com relação à renda da vítima, metade, 50\%, recebia entre 01 a 03 salários mínimos, e 30\% das mulheres possuíam renda abaixo de 01 salário mínimo. Outra parcela inferior recebe mais de 03 salários mínimos.

Quanto à escolaridade, prevaleceram as mulheres que não chegaram a concluir o ensino fundamental, correspondendo a $48 \%$ do universo. As que concluíram o ensino fundamental corresponderam a $26 \%$, as que concluíram o ensino médio totalizaram $24 \%$ e a taxa de analfabetismo foi de $2 \%$. 
Ainda na tabela 1, observamos que, com relação à condição de trabalho, a maioria, $64 \%$, desenvolvia algum tipo de trabalho remunerado. Nessa proporção estão incluídas as empregadas no mercado formal, as trabalhadoras informais e as autônomas. Embora não tenha sido possível levantar as características com relação à situação de emprego no que diz respeito ao contrato de trabalho, pois esse tipo de informação não consta das fichas, acreditamos que muitas mulheres estivessem no mercado informal, devido aos tipos de atividade que declararam realizar, mais associadas à informalidade. Com ocupaçôes ligadas ao emprego doméstico, como lavadeira, cozinheira e faxineira, também apareceram com bastante frequência, assim como as de vendedoras, manicuras e costureiras, atividades tradicionalmente femininas e de baixa remuneração.

Quanto à caracterização dos casos de violência, podemos observar na tabela 2 que prevalece a violência moral e psicológica, com $74 \%$ dos casos e, em segundo lugar, a violência física, com $18 \%$. Ressalta-se também que, dos 50 casos analisados, $08 \%$ referem-se a mulheres que vivenciaram outro tipo de violência (sexual, patrimonial, entre outras).

Tabela 2 - Caracterização dos casos atendidos no Centro de Atendimento à Mulher de Vilhena (R0), conforme tipo de violência e ambiente em que ela ocorreu. (2018)

\begin{tabular}{|c|c|c|}
\hline Tipo de violência & Quantidade & Percentual \\
\hline Moral e psicológica & 37 & 74 \\
\hline Física & 09 & 18 \\
\hline Outras & 04 & 08 \\
\hline Ambiente em que Ocorreu a Agressão & & 96 \\
\hline Ambiente doméstico & 48 & 02 \\
\hline Na rua & 01 & 02 \\
\hline Outro local & 01 & 0 \\
\hline
\end{tabular}

Com relação ao ambiente em que ocorreu a violência, quase a totalidade dos casos (96\%) ocorreu no ambiente doméstico, resultado que se assemelha ao encontrado em outras pesquisas (Barsted, 1998; Diniz e cols., 1999; Deslandes e cols., 2000). Assim, o lar parece constituir-se no espaço privilegiado da violência contra a mulher, onde, resguardado da interferência de outras pessoas, o agressor conta ainda com o medo e a vergonha da pessoa agredida em denunciá-lo.

Tabela 3 - Caracterização dos casos atendidos no Centro de Atendimento à Mulher de Vilhena (RO), conforme tipo de vínculo afetivo da vítima com o agressor e período de convivência, 2018.

\begin{tabular}{|c|c|c|}
\hline Tipo de vínculo afetivo da vítima com o agressor & Quantidade & Percentual \\
\hline Marido ou companheiro & 36 & 72 \\
\hline Ex-marido ou ex-companheiro & 08 & 16 \\
\hline Ex-namorado & 06 & 12 \\
\hline Período de Convivência & & 24 \\
\hline Menos de 03 anos & 12 & 40 \\
\hline Entre 05 e 10 anos & 20 & 30 \\
\hline Entre 12 a 18 anos & 15 & 06 \\
\hline Acima de 20 anos & 03 & \\
\hline
\end{tabular}

Os principais agressores são os atuais maridos ou companheiros, que, de acordo com a tabela 3, correspondem a 72\%. Agregando-se a esse tipo de agressor os namorados, ex-maridos ou ex-companheiro e ex-namorados, a proporção desse conjunto, denominado de relação conjugal, perfaz os $100 \%$ das agressóes encontradas nas fichas das mulheres atendidas nesse período. 
Quanto ao período de convivência em situação de violência destaca-se que $40 \%$ das vítimas convive ou conviveu um período de 05 até 10 anos com o agressor, seguida por $30 \%$ que vive ou viveu entre 12 a 18 anos. Uma proporção de $24 \%$ dos casos refere-se a mulheres que sofrem agressôes há menos de 03 anos. Foram registrados 03 casos de mulheres que relataram sofrer violência há mais de 20 anos. Este quadro reflete bem o processo de rotinização da violência (Organização das Nações Unidas, 1996). As agressóes vão se tornando cada vez mais frequentes, e as sequelas, que podem ser visíveis como as resultantes da agressão física, ou emocionais, vão aos pouco se agravando.

Esses períodos acima descritos são considerados longos demais em situação de violência. Isso prova que falta muito para rompermos com esse silencio das vítimas de violência doméstica. No sentido de eliminar este mal que ano após anos tem ceifado vidas em todo Brasil.

Conforme consta nas fichas de atendimento das mulheres investigadas a Delegacia da Mulher é o órgão que mais encaminha mulheres para o CAM, tendo sido responsável pelo encaminhamento de $50 \%$ dos casos. Em proporçóes bem menores aparecem ainda, como responsáveis pelo encaminhamento, outras usuárias do serviço, parentes, amigas/os ou conhecidas/os, profissionais ligados a serviços, tanto públicos quanto privados, das áreas de psicologia, assistência social, saúde e direito.

Porém, percebeu-se em conversa com uma profissional do serviço social Centro de Atendimento a Mulher, que a rede de atendimento/encaminhamento de mulheres vítima de violência, é falha e muitas vezes omissa por não encaminhar essas mulheres para atendimento no CAM, ela relatou que muitos casos que passa pela delegacia da mulher nem sempre chega até o CAM. Talvez esse número de 50 mulheres no período investigado poderia ser bem superior, se as demandas fosse encaminhada.

A profissional ainda cita que os serviços de saúde - prioritariamente o hospital - aparecem como responsáveis por apenas $4 \%$ dos encaminhamentos. Nota-se que falta estratégias na integração da rede de atendimento público, pois, o setor de saúde deveria nesse caso ser vistos como estratégicos, no que diz respeito às açóes de prevenção da violência contra a mulher. Já que para Schraiber e D'Oliveira, (1999) as mulheres que sofrem violência têm maior probabilidade de apresentarem problemas de saúde, logo se deve supor que elas procuram com mais frequência os serviços de saúde.

Gomes e cols. (2002), em pesquisa sobre a abordagem dos maus-tratos contra crianças e adolescentes em uma unidade pública de saúde do Rio de Janeiro, chamam a atenção para o fato de que esta questáo ainda náo foi incorporada nos currículos de graduaçáo, deixando uma lacuna na formação desses profissionais. Os autores apontam um certo despreparo dos profissionais de saúde para lidar com a questão, comprometendo a identificação dos casos e a realização de atendimentos e de encaminhamentos adequados. Acreditamos que no caso da violência contra a mulher, guardadas as devidas proporçóes, esse mesmo despreparo dificulte uma intervenção mais efetiva dos profissionais de saúde quanto ao reconhecimento dos casos de violência, ao atendimento e ao encaminhamento das mulheres aos demais serviços de apoio nessa área.

\section{CONSIDERAÇÕES FINAIS}

Com a realização deste estudo foi possível evidenciar que os motivos da reincidência das mulheres vítimas de violência doméstica, a partir das informaçôes constantes das fichas de atendimento do CAM de Vilhena/RO, estão associados a diversos fatores, sendo eles emocionais e culturais, baixa escolaridade, dependência financeira, agregando-se à significativa inefetividade de programas públicos, voltados ao amparo destas mulheres. 
Embora nesta investigação tenha sido constatado um público de mulheres basicamente de camadas de baixa renda, sabe-se que a dependência econômica não é o único fator que leva as mulheres a permanecerem convivendo com homens agressores. Para entender os determinantes dessa situação é importante considerar também a dependência emocional (Saffioti, 1997) e os aspectos culturais associados à construção social dos papéis femininos e masculinos que determinam a forma como se estabelecem as relações de dominação e submissão entre os gêneros (Gregori,1993).

No decorrer da pesquisa foi possível perceber que a violência doméstica, apesar de ser mal que tem ceifado vidas ao longos do anos, não é uma doença, porém pode adoecer quem convive neste realidade. Por exemplo, os aspectos emocionais pode ter influência decisiva na baixa autoestima presente na vida dessas mulheres. Desta forma, a mulher poderá passar a desacreditar de si mesma e a enxergar-se como uma sombra do companheiro agressor.

A dependência financeira e o quesito escolaridade, por sua vez, possuem um grau de importância no caso de reincidência de violência doméstica, pois a falta de instruçáo e de apoio, aliadas a sua baixa autoestima, faz com que a mulher sinta-se incapaz de levar sua vida adiante sem o companheiro.

A complexidade que envolve a questão da violência contra a mulher, principalmente a reincidência, enfoque deste trabalho, exige açôes capazes de dar conta das inúmeras demandas apresentadas, o que implica a necessidade de articulação entre diferentes áreas de conhecimento e de atuação. Assim, os serviços de atendimento às mulheres em situação de violência são de fundamental importância para o enfrentamento desse problema, sendo imprescindível que estes estejam articulados com os serviços de saúde no desenvolvimento de açôes preventivas e assistenciais, na perspectiva da atenção integral à mulher.

Outro fator importante que se percebeu neste estudo é que há poucas políticas públicas voltada para atendimento do agressor, as açóes estão muito focadas no fator punitivo criado pelas legislaçôes. Talvez, a grande solução para evitar violência doméstica, principalmente, as reincidências.

Conclui-se, portanto, a necessidade de trabalhar a violência, antes mesmo que ela aconteça, nas escolas, nos meios de comunicação, nas empresas e nas redes sociais, tal qual preconiza a Lei Maria da Penha, que com seu caráter pedagógico visa contribuir para a educação de geração para geração. Há a necessidade também, de capacitar profissionais, a fim de que eles entendam o problema náo como algo individual ou pessoal e sim como uma questáo sociocultural, permeada por anos.

Acredita-se que muitas das mulheres agredidas sofram silenciosamente e não peçam ajuda. Para elas, é difícil dar um fim na situação de violência em que vivem, sentem-se envergonhadas e outras dependem emocionalmente ou financeiramente do companheiro agressor; muitas acreditam ter acontecido "só daquela vez" ou, no fundo, imaginam-se culpadas pela violência; outras se calam em função dos filhos, ou até mesmo por medo de apanhar e sofrer ainda mais e, ainda, temem por prejudicar o agressor, que pode ser preso ou censurado pela sociedade.

Esta pesquisa teve o intuito de investigar os fatores que contribuem para a reincidência da violência doméstica. Fica, a partir deste estudo, o desejo de que ele venha contribuir efetivamente, para mostrar as possíveis causas que contribuem para a reincidência da violência doméstica, sobretudo, desvincular essa temática dos preconceitos e garantir e reconhecer, no âmbito do poder público, a problemática da violência contra a mulher enquanto questão de políticas públicas específicas, pois, as intervençôes ainda estão mais associadas às áreas de segurança pública e assistência social. 


\section{REFERÊNCIAS}

BARSTED, L. de A. L. Uma vida sem violência é um direito nosso: propostas de açâo contra a violência intrafamiliar no Brasil. Brasília: Comitê Interagencial de Gênero/ONU/Secretaria Nacional dos Direitos Humanos/ Ministério da Justiça, Brasília, 1998.

BRASIL. Lei No 11.340, De 7 de Agosto de 2006. Disponível em<http://www.planalto.gov.br/ccivil_03/_ Ato2004-2006/2006/Lei/L11340.htm->Acesso em:11/06/2019.

CUNHA, Rogério Sanches. Violência Doméstica. Lei Maria da Penha (Lei 11.340/2006 de combate a violência doméstica e familiar contra a mulher. São Paulo: Revista dos Tribunais, 2007.

DESLANDES, S. F.; GOMES, R.; SILVA, C. M. F. P. da. Caracterização dos casos de violência doméstica contra a mulher atendidos em dois hospitais públicos do Rio de Janeiro. Cadernos de Saúde Pública, Rio de Janeiro, v.16, n.1, jan-mar, 2000.

GREGORI, M. F. Cenas e queixas: um estudo sobre mulheres, relaçóes violentas e a prática feminista. Rio de Janeiro: Paz e Terra. São Paulo: ANPOCS, 1993.

GOMES, R. et al. A abordagem dos maus-tratos contra a criança e o adolescente em uma unidade pública de saúde. Ciência \& Saúde Coletiva, Rio de Janeiro, v.7, n.2, p. 275-283, 2002.

MACHADO, C.; GONÇALVES, R. A. Violência e Vítimas de Crimes. Coimbra: Quarteto, 2003.

QUEIROZ, Fernanda Marques de. Lei Maria da Penha: Conquista legal, desafios à sua implementaçáo. Seminário Fazendo Gênero 8 - Corpo, Violência e Poder. Florianópolis. 2008. Disponível em: <http:// www.fazendogenero.ufsc.br/8/sts/ST11/Fernanda_Marques_de_Queiroz_11.pdf $>$. Acesso em 25/05/2019.

SAFFIOTI, Heleieth I. B.; ALMEIDA, Suely Souza. Violência de gênero: poder e impotência. Rio de Janeiro: Livraria e Editora Revinter, 1995.

SCHRAIBER, Lilia B; D’OLIVEIRA, Ana Flávia L. Paula. Violência contra a mulher: interfaces com a saúde. Interfaces: Comunicação, Saúde, Educação, v.3. n.5, pp. 11-27, 1999.

SPM - Secretaria de Políticas para Mulheres. Pacto Nacional de Enfrentamento à Violência contra as Mulheres. 2010 (Enfrentamento à violência contra as mulheres; v. 2) Brasília: Brasília: Presidência das República/ Secretaria de Políticas para as Mulheres, Secretaria Nacional de Enfrentamento à Violência Contra as Mulheres. 52 páginas.

TAQUETTE, Stela R. (Org.) Mulher Adolescente/Jovem em Situação de Violência. Brasília: Secretaria Especial de Políticas para as Mulheres, 2007.

TELES, Maria Amélia de Almeida; MELO, Mônica de. O que é violência contra a mulher. Coleção Primeiros Passos. São Paulo: Brasiliense, 2003. 